\title{
MODAl ANAlysis APPLiEd TO EleCtric GUITAR DeSign INFLUENCE ON MANUfaCtURING PARAMETERS
}

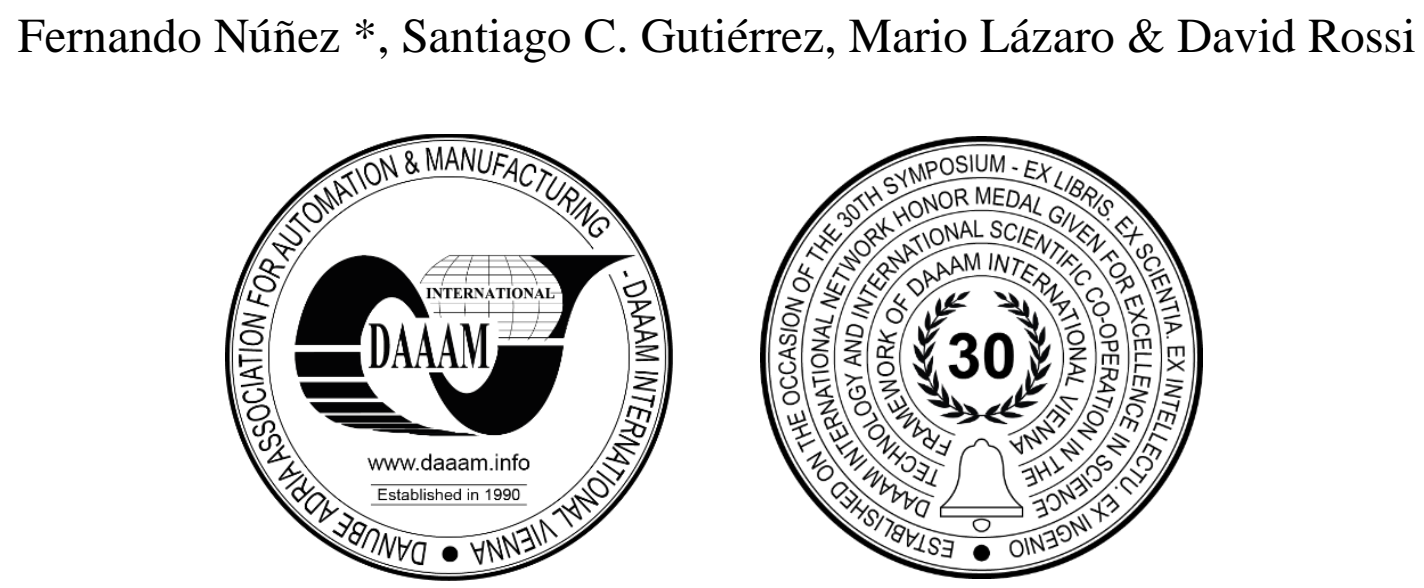

This Publication has to be referred as: Fernando J., N[unez] C[alzado]; Gutierrez Rubert, S[antiago] C[arlos]; Lazaro, M[ario] \& Rossi, D[avid] (2020). Modal Analysis Applied to Electric Guitar Design Influence on Manufacturing Parameters, Proceedings of the 31st DAAAM International Symposium, pp.0520-0529, B. Katalinic (Ed.), Published by DAAAM International, ISBN 978-3-902734-29-7, ISSN 1726-9679, Vienna, Austria

DOI: $10.2507 / 31$ st.daaam.proceedings.072

\begin{abstract}
Modal analysis techniques applied to obtain solid body guitar natural frequencies provides valuable information to optimise the instrument design and manufacturing process, especially on thin line body models. Using the iconic Fender Telecaster model, and introducing a basic manufacturing parameter set, we analyse the correlation of these parameters and the frequency values obtained on each case. Physics behind the guitar signal modification due to instrument structure is based mainly on the coupling or transduction of the vibrational energy of the string to the whole guitar assembled body. Vibroacoustic studies over solid body guitar have been treated by other researchers, covering a wide range of approaches. Our research is based on a dual design-manufacturing/sound analysis perspective, focusing on guitar makers and luthier needs. Frequency values obtained on each case, and the developed finite element model, generated useful data. This information has been used to prove its validity for the successful manufacturing of three new improved instruments involving the luthier on the design modification phase. Relation of modal frequency values and the manufacturing parameters (wood type, body and neck thickness, internal cavity characteristics) exists in the CAD/CAE environment. It can be modelled and simulated to create a digital mock-up of the instrument. Parameter correlations agree with empirical luthier knowledge remarking two traditional discussion areas, the selection of wood to manufacture guitar parts and the internal cavity design.
\end{abstract}

Keywords: Electric guitar manufacturing; modal analysis; guitar design parameters; vibroacoustic; thin line body.

\section{Introduction}

This article begins an investigation whose final aim is to create a digital mock-up of the electric guitar to improve the design/manufacturing process. Based on a mechanical/sound analysis perspective, this new approach centres on the simulated model, instead of using the real instrument or physical models. Studies on electric guitar have been focused on the various parts that make up the signal chain independently, string vibration [5], pickup response [8], external effects applied to the signal chain [9], and the influence of amplification [10]. Research environment review shows that physics related to electric guitar, modal analysis tools and psychoacoustic tests, have been applied widely [1],[3]. 
Nevertheless, there is a clear uncovered area on the use of CAD/CAE tools applied to the design and manufacturing process of the instrument. Arthur Paté [1] and Benoit Navarret [3] studies establish an updated reference to structure the different stages of development of the digital guitar mock-up.

A detailed reference reading situates the vibrational component in the first position to start the digital mock-up investigation. Vibrational behaviour in the guitar assembly can be classified into passive (vibrational response of steady parts like body and neck), and active (string vibration), so we decide to start the digital mock-up studying this passive component, using modal analysis as tool and coupling phenomenon as the primary object of study.

The effect of manufacturing characteristics on the guitar signal is based mainly on the coupling or transduction of the vibrational energy of the string, to the structure of the instrument itself. The coupling has been widely studied in instruments like the classical guitar, or the harpsichord, for example, the coupling on the solid-body electric guitar is treated extensively on [5], but not considering the whole instrument assembly as a modifying filter of the signal produced by strings-pickup pair. In the present study, a 3D CAD model was created, including a basic set of manufacturing parameters to perform a preliminary check of their influence on the modal frequency values, establishing correlations between parameters and response.

The relation between the design and manufacturing process is clearly defined, every design characteristic affects the manufacturing process (in time and cost), and of course, in terms of sound and aesthetics of the instrument. Why not plan the cycle backwards?, creating a Computer Aided Engineering model to simulate manufacturing modifications needed to adapt and improve the instrument design to the desired sound, saving time and errors

This article creates the foundations to introduce a more scientific perspective on the instrument design phase using modal behaviour as a distinctive fingerprint of the instrument. The main objective has been to model and prove the relations between modal frequencies and manufacturing parameters and establish the guidelines to future research stages.

\section{Methodology}

The first step on performing a dynamic analysis is to determine the natural frequencies and mode shapes of the structure vibration. These results characterise the basic dynamic behaviour, and are a clear indication of how the system will respond to dynamic loading. The natural frequencies of a structure are the values at which naturally tends to vibrate if it is subjected to a disturbance. The deformed shape of the structure is termed its normal mode of vibration at a specific natural frequency.[6]. In this article, modal analysis is applied to the two main components of the electric guitar assembly separately as the preliminary stage of full assembly analysis. Table 1 shows images of both parts and main characteristics.

\begin{tabular}{|l|c|c|c|}
\hline \multicolumn{2}{|c|}{ GUITAR BODY } & \multicolumn{2}{c|}{ GUITAR NECK } \\
\hline \multicolumn{1}{|c|}{} & & \\
\hline
\end{tabular}

Table 1. Fender Telecaster body and neck main characteristics.

Simulations in this article are performed using NX Solver 103 (Normal Modes Analysis, Solution 103), a tool included on the NX Nastran Basic package that determines the vibration characteristics of a structure generating modes shapes and frequency values. Procedure steps are showed on the following scheme (Fig. 1), it starts extracting the original drawings information, to generate de 3D CAD and create the FEM model. It ends with solving each case and analysing the results obtained. The article is structured around the CASE ID concept; each case is composed of one manufacturing variable, one parameter (Table 3) value, and the frequency results generated by Solver 103. Each CASE ID is numbered as V1, $\mathrm{V} 2, \mathrm{~V} 3, \ldots \mathrm{V} 9$, for cavity cases, and $0,1,2,3,4$ on the rest (geometric parameters cases and wood type cases).

The frequency range of the instrument (Fig. 2) is introduced as a contour condition to limit the number of frequency values calculated by the solver 103 used in the study. First four values inside the range for each case (F1, F2, F3, F4) are included on each results table. Fig. 2. shows graphically the frequency range of sounds produced by the guitar in standard tuning $(\mathrm{A}=440 \mathrm{~Hz})$, it starts with $82.412 \mathrm{~Hz}$ value of E string and finishes with $1174.624 \mathrm{~Hz}$. of sixth string last neck fret. 
Fender Telecaster original drawings
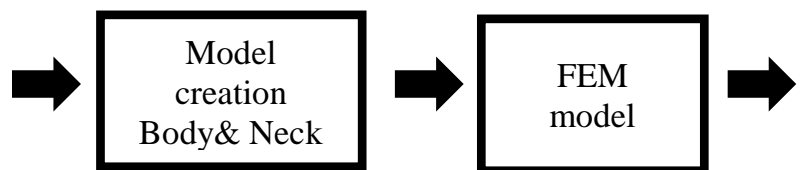

Modal analysis using NX solver SOL 103

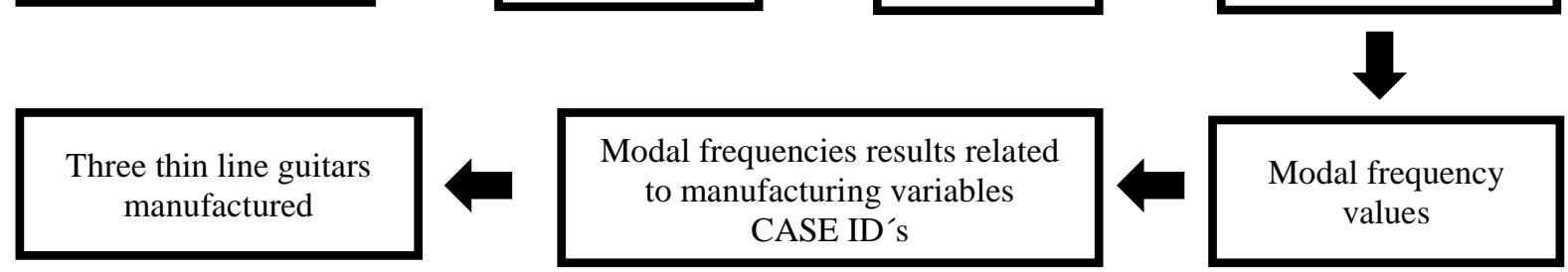

Fig. 1. General procedure scheme

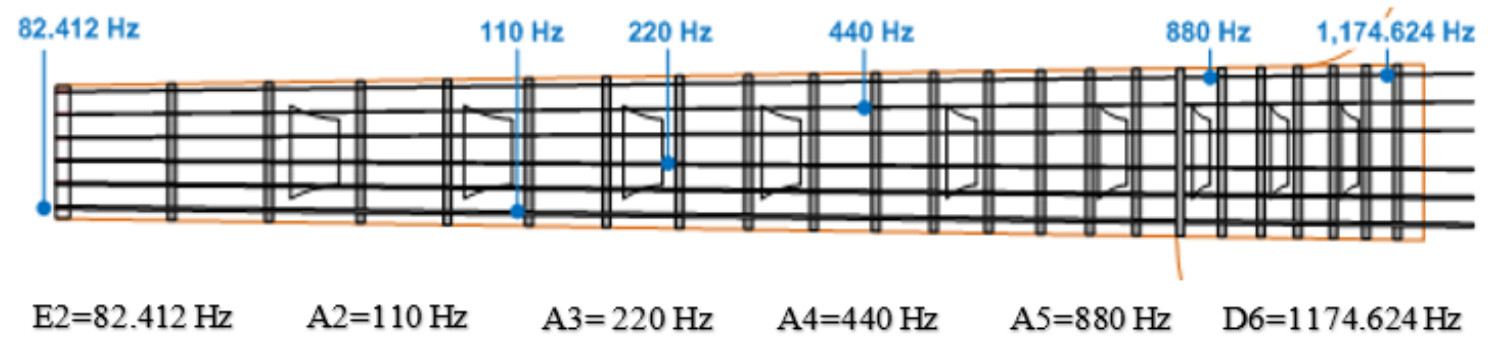

Fig. 2. Frequency range of electric guitar.

Each case results and comments are located on individual tables, identifying the following columns:

FEM CASE ID: labels the manufacturing case modelled, using a PARAMETER NAME VERSION structure.

F1, F2, F3, F4: First four modal frequencies + coefficient of variation (CV) for each frequency column.

PARAMETER: Manufacturing parameter and related units.

GRAPHICAL INFORMATION: a quick reference to frequency- parameter correlation. (Table 5).

\begin{tabular}{|c|c|c|c|}
\hline DIRECT RELATION & INVERSE RELATION & NO RELATION & COMPLEX RELATION \\
\hline$\propto$ & $1 / \propto$ & $\varnothing$ & $\mathrm{f}(\propto)$ \\
\hline
\end{tabular}

Table 2. Symbols used on the results table to indicate frequency - manufacturing parameter relation.

CV: coefficient of Variation $(\mathrm{CV})$, defined as a ratio of the standard deviation to the sample mean, is included on each column in percentage form to provide information about frequency values variability around the sample mean. This value identifies if a frequency band has a behaviour suitable for a more detailed analysis. The results presented in this article have been generated solving modal frequencies exclusively on the idealised three-dimensional models, the analysis of real instruments manufactured is scheduled for the following research stages, using an extended manufacturing parameter set.

\section{Model Creation}

For 3D modelling of the different parts of the guitar, we used the original two-dimensional drawings and instrument design patents. In 1951, Leo Fender created and patented this original guitar. His primary objective was to produce an economical product, with a simple shape that could be manufactured using standard woodworking manual operations [7]. For the model creation, we used Siemens NX. The simplicity of Leo's instrument design allows using a scanned version of the original drawing as a reference image. The guitar body shape and the cavities on it, were modelled using simple extrusion functions. Guitar neck is clearly defined on the drawings, so it can be shaped directly without using other external data.

Hollow body versions of the instrument include internal cavities that modify weight, guitar balance, and sound characteristics. Therefore, the shape, size and location of this internal cavities are critical variables in the design process. During the research, a manufacturing item was developed simultaneously by our luthier co-author, and the results obtained from virtual models were applied on the fabrication of three new guitars. Manufacturing case is explained more detailed on point 4.4. Fig. 3. shows a finished NX model of the modified version and different stages of the CNC milling process, including final finish and assembly with neck and hardware. 


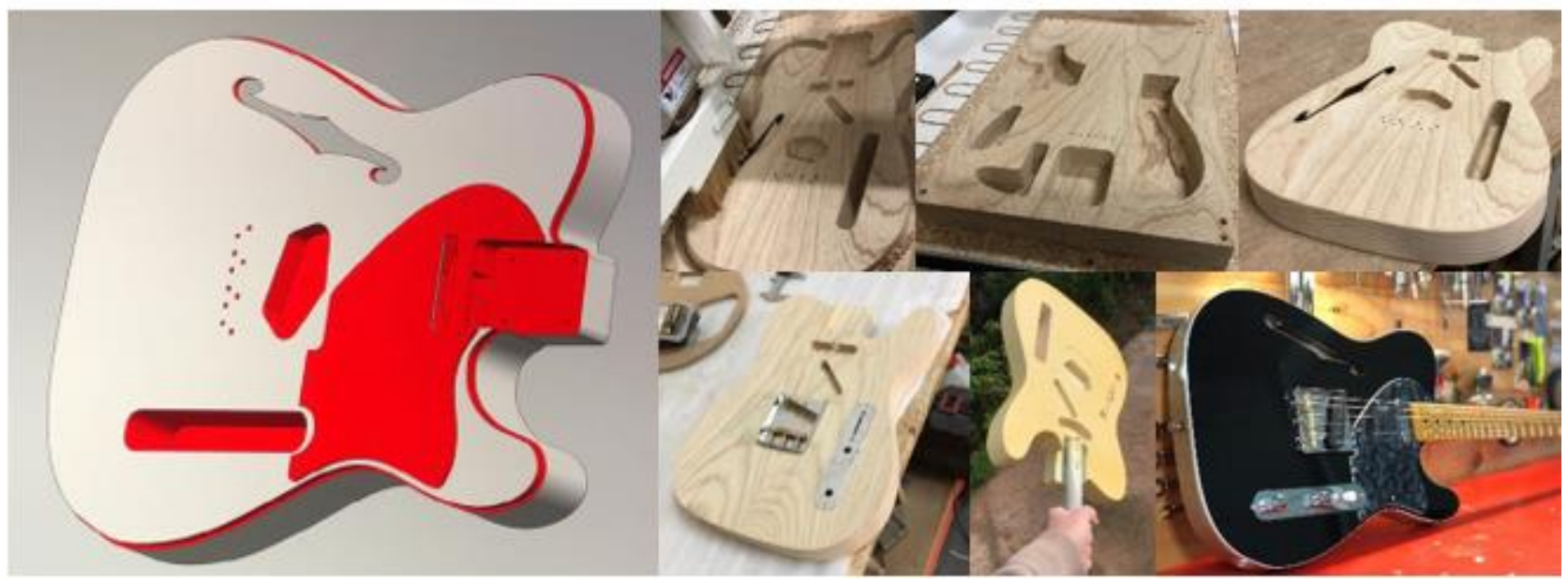

Fig. 3. 3D model image and different manufacturing stages

\subsection{Fem Model}

Modal frequency values are calculated using Nastran software integrated on Siemens NX. Each simulation file needs a defined contour conditions (Table 2) to execute the analysis correctly and generate representative results. Modal analysis solver demands an error-free three-dimensional geometry, an accurate material definition, clear geometric constraints, an error-free mesh and 40 minutes of computing time, using a $16 \mathrm{~Gb} / \mathrm{SSD}$ Intel i7 system for each case solved.

\begin{tabular}{|l|c|c|c|c|c|c|}
\hline & $\begin{array}{c}\text { MESH } \\
\text { SIZE }\end{array}$ & $\begin{array}{c}\text { ELEMENT } \\
\text { SIZE }\end{array}$ & $\begin{array}{c}\text { ELEMENT } \\
\text { SHAPE }\end{array}$ & MATERIAL & CONSTRAINTS & SOLVER \\
\hline NECK & 25993 & $5 \mathrm{~mm}$ & Tetrahedral & acc. wood type & Fixed on neck joint & Nastran 103 \\
\hline BODY & 163661 & $5 \mathrm{~mm}$ & Tetrahedral & acc. wood type & Fixed on neck joint & Nastran 103 \\
\hline
\end{tabular}

Table 3. FEM model main data and conditions.

Results generated using the 103 solver are mode shapes and frequency values. In this paper, we present only the first four frequency values restricted to the guitar fundamental frequency interval (Fig 2) to generate first general guidelines. Basic parameter set characteristics and description are defined on (Table 3):

\begin{tabular}{|c|c|c|l|}
\hline PARAMETER NAME & TYPE & UNITS & \multicolumn{1}{|c|}{ DESCRIPTION } \\
\hline CAVITY VOLUME & Numerical value & $\mathrm{cm} 3$ & Total volume of body internal cavities. \\
\hline CAVITY LAYOUT & Attribute & -- & Type of cavity layout \\
\hline CAVITY SHAPE & Attribute & -- & Shape of internal cavities \\
\hline BODY THICKNESS & Numerical value & $\mathrm{mm}$ & Body general thickness in mm \\
\hline BODY WOOD & Numerical value & $\mathrm{mm}$ & Wood used on body manufacturing \\
\hline NECK THICKNESS & Numerical value & $\mathrm{mm}$ & Neck general thickness in mm \\
\hline NECK WOOD & Numerical value & $\mathrm{mm}$ & Wood used on neck manufacturing \\
\hline WOOD CUT & Attribute & -- & Wood cut type. Constant value in this set. \\
\hline
\end{tabular}

Table 4. Basic manufacturing parameter set.

Fig. 4 shows various finite element model information on each guitar part for better understanding, including axis orientations on each model. Black arrows help to identify mechanical properties direction, and red arrow areas locate neck joint zone situation. Directions are included for better definition and modelling of two essential wood properties, orthotropy in mechanical properties (Table 4) and woodcut used (Fig. 5).

The three-dimensional model reference axis in the CAD software shares orientation with FEM model (Fig. 4), so this causes a virtual flat-sawn woodcut. If the axis orientation change, the result will model one of the other woodcuts available (Fig. 5). Element size used is the same for body and neck $(5 \mathrm{~mm})$, this value was suggested by the FEM software and produced a reasonable accuracy in the results, without excessive computational time. Neck joint zone defines the static zone where no displacements are allowed due to the restriction applied to the FEM model. 

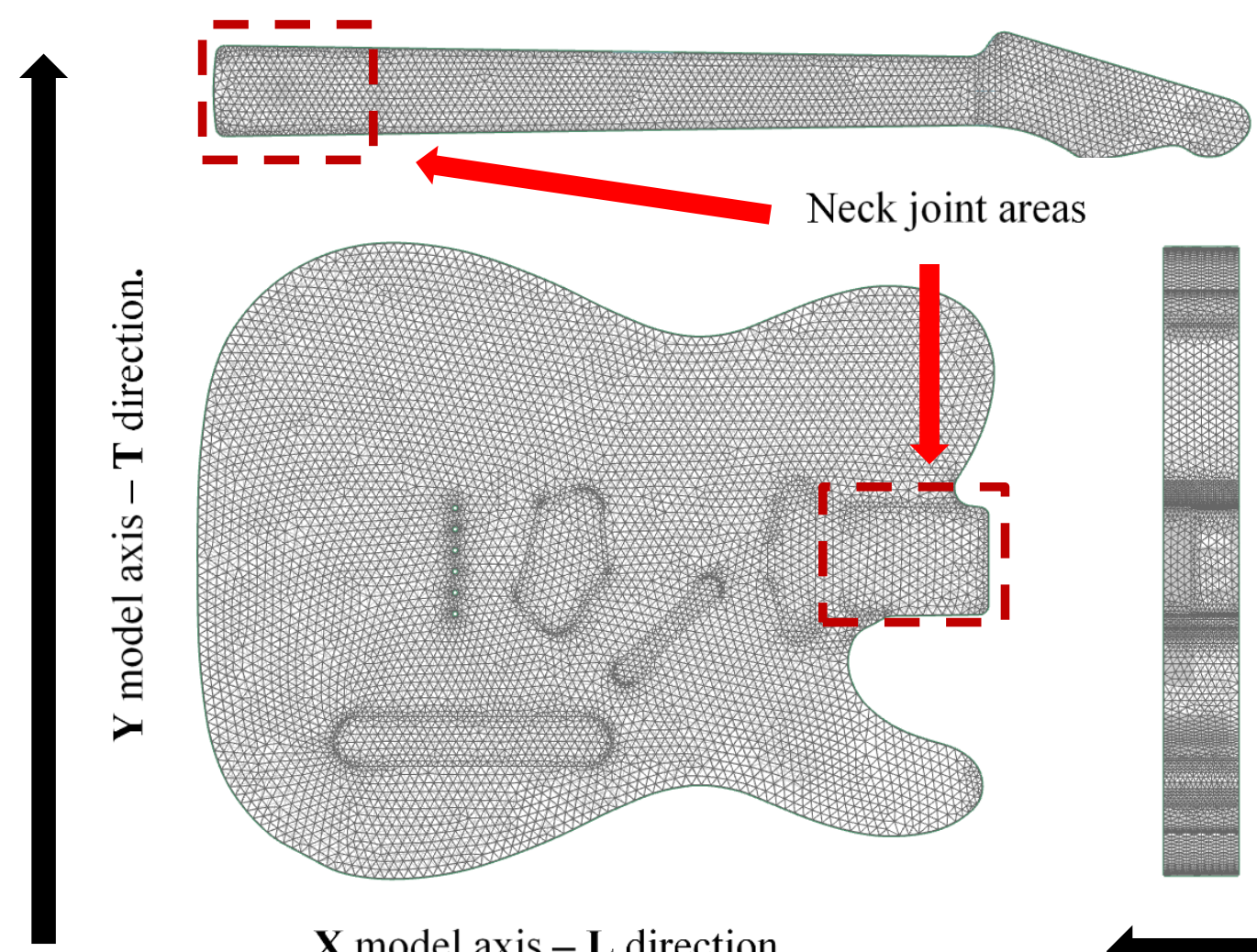

\section{Neck joint areas}
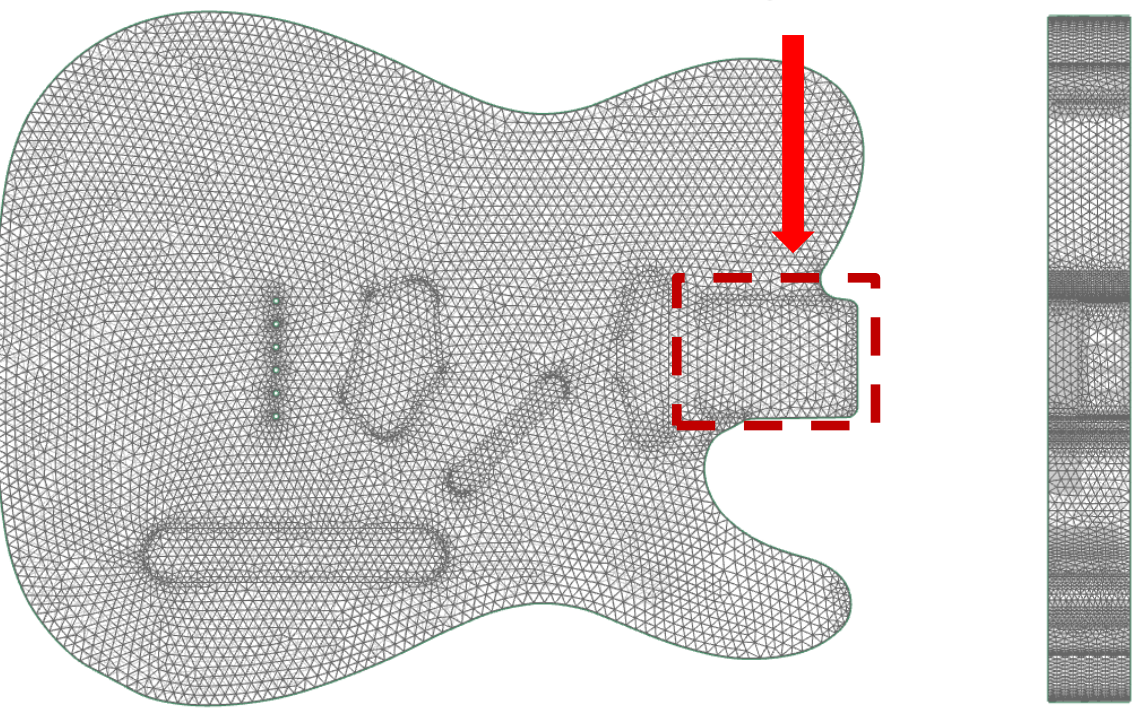

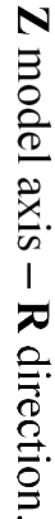

$\mathbf{X}$ model axis - $\mathbf{L}$ direction.

Fig. 4. NX Nastran model mesh. Axis orientation and neck joint location.

\subsection{Material definition}

Wood is a material with special characteristics and behaviour; the correct definition of its mechanical properties is essential to obtain representative results in the modal analysis simulation. It is defined as an orthotropic material, so it has different mechanical properties in the three orthogonal directions. The longitudinal direction $\mathbf{L}$ is parallel to the arrangement of fibres in the wood, $\mathbf{R}$ is normal to the growth rings of the tree, and $\mathbf{T}$ is perpendicular to the fibres and tangent to the growth rings. [2] Nine parameter values are needed to define wood mechanical properties, L, T and R subindexes refers to each one of the wood directions (Fig. 4 and Fig. 5). Table 4 shows wood density $(\rho)$ (expressed in $\left.\mathrm{gr} / \mathrm{cm}^{3}\right)$, three moduli of elasticity in each direction $\left(\mathrm{E}_{\mathrm{L}}, \mathrm{E}_{\mathrm{T}}, \mathrm{E}_{\mathrm{R}} / \mathrm{MPa}\right.$ units), three moduli of rigidity $\left(\mathrm{G}_{\mathrm{LR}}, \mathrm{G}_{\mathrm{LT}}, \mathrm{G}_{\mathrm{RT}} / \mathrm{MPa}\right.$ units) and three Poisson's ratio values $\left(\mu_{\mathrm{LR}}, \mu_{\mathrm{LT}}, \mu_{\mathrm{TR}}\right)$ on each direction too. [4]

\begin{tabular}{|c|c|c|c|c|c|c|c|c|c|c|}
\hline Wood & $\boldsymbol{\rho}$ & $\mathbf{E}_{\mathbf{L}}$ & $\mathbf{E}_{\mathbf{T}}$ & $\mathbf{E}_{\mathbf{R}}$ & $\mathbf{G}_{\mathbf{L R}}$ & $\mathbf{G}_{\mathbf{L T}}$ & $\mathbf{G}_{\mathrm{RT}}$ & $\boldsymbol{\mu}_{\mathrm{LR}}$ & $\boldsymbol{\mu}_{\mathrm{LT}}$ & $\boldsymbol{\mu}_{\mathrm{TR}}$ \\
\hline Ash & 0.60 & 13200 & 1056 & 1650 & 1439 & 1016 & 330 & 0.371 & 0.44 & 0.36 \\
\hline Maple & 0.57 & 12430 & 833 & 1740 & 1653 & 920 & 311 & 0.434 & 0.509 & 0.354 \\
\hline Walnut & 0.55 & 12760 & 715 & 1353 & 1085 & 791 & 268 & 0.495 & 0.632 & 0.378 \\
\hline Mahogany & 0.53 & 11605 & 743 & 1242 & 766 & 998 & 325 & 0.314 & 0.533 & 0.326 \\
\hline Birch & 0.62 & 15290 & 765 & 1193 & 1131 & 1040 & 260 & 0.426 & 0.451 & 0.426 \\
\hline Poplar & 0.42 & 11990 & 516 & 1103 & 899 & 827 & 132 & 0.318 & 0.392 & 0.329 \\
\hline
\end{tabular}

Table 5. Wood material definition mechanical parameters.[4]

The woodcut used in body and neck is a parameter defined at the earliest manufacturing stages; it's based mainly on the material cost, mechanical stability and vibration transmission desired. According to the basic parameter set (Table 3), all the modelled part fits the flat-sawn woodcut on this paper cases, rest of woodcuts will be introduced in the next research stages. 

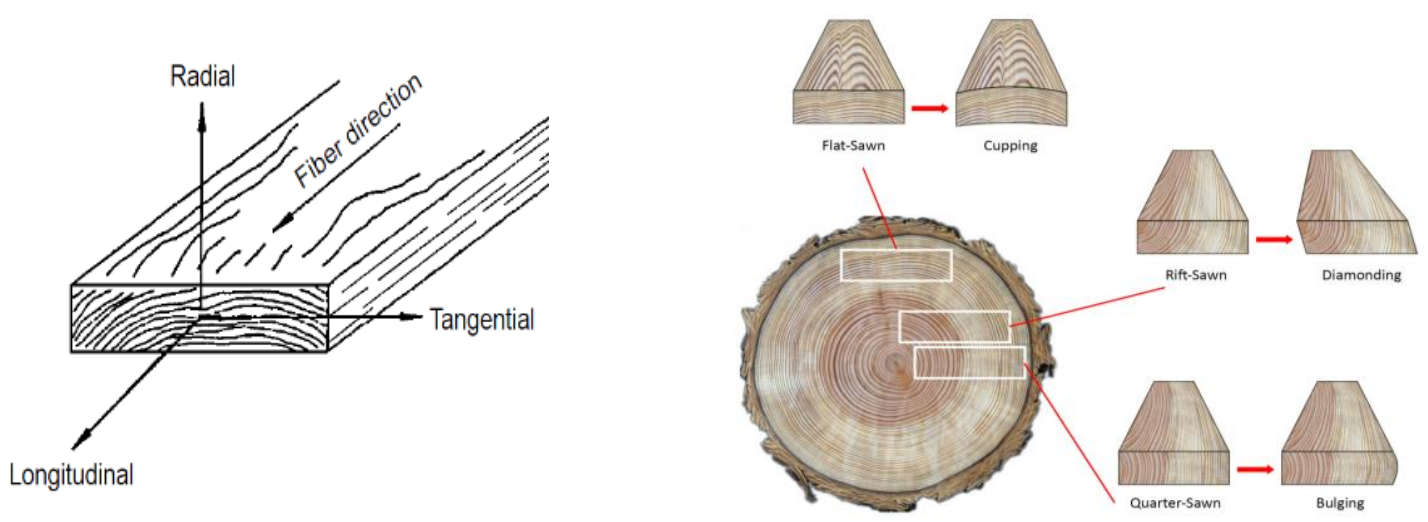

Fig. 5. Wood fibre orientation and woodcut types. [4]

\section{Results}

Analysis of results is presented mixing data from two different sources: First one, mechanical perspective, that directly uses the reference equation (1) to discuss and check if values and correlations observed are correct related to the expression terms. The second one, luthier approach, that introduces professional experience to confirm that results obtained are coherent with existing knowledge. We use (1) from Dynamic Analysis Guide [6] to express the mathematical relation of the modal frequencies with magnitudes like (cross-section inertia moment, material density, material crosssection surface and Young's modulus). These magnitudes define physically, and geometrically the guitar parts studied. Different balances between $E I_{\text {bend }}$ and $\rho S$ terms generate direct/inverse relations depending on each one relative values.

$$
f_{i} \propto \sqrt{\frac{E I_{\text {bend }}}{\rho S}}
$$

$f_{i}=$ modal frequency. value, $\mathrm{E}=$ Young's modulus, $I_{\text {bend }}=$ inertia moment, $\rho=$ density and $S=$ cross section area.

\subsection{Cavity cases results}

Table 6 shows the transparent images of each case model for different cases for better understanding.
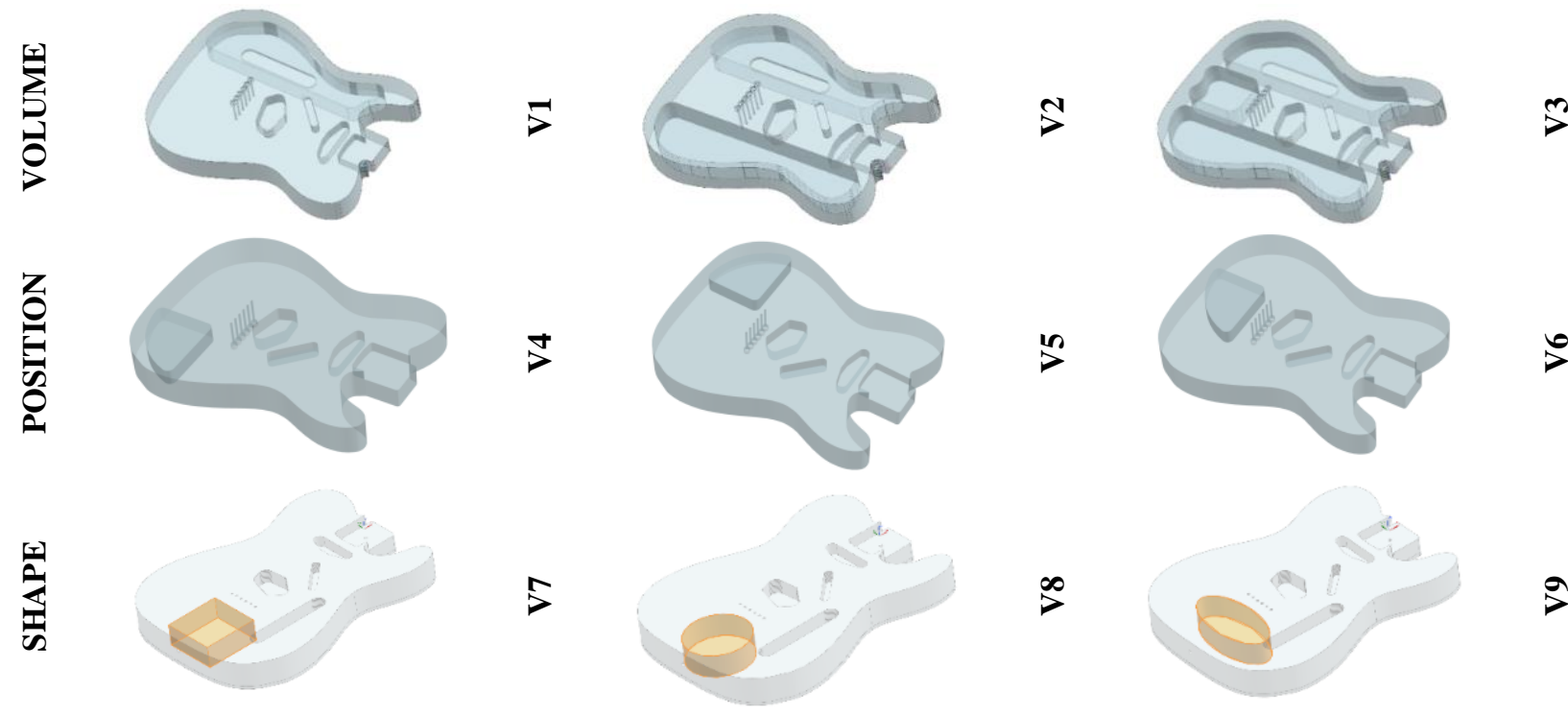

Table 6. Cavity cases graphical layout.

Results of cases emulating internal cavities are exposed here. Different setups were created to represent the most common manufacturing decisions (size, shape and position). These three-dimensional models aim is to create extreme design proposals, to make the correlation evident.

Table 7 shows the frequency values calculated for the different cavity cases. 


\begin{tabular}{|c|c|c|c|c|c|c|}
\hline FEM CASE ID & F1 (Hz) & F2 (Hz) & F3 (Hz) & F4 (Hz) & Volume $\left(\mathrm{cm}^{3}\right)$ & Relation \\
\hline CAVITY VOLUME V1 & 482.3 & 527.6 & 961.6 & 1090.5 & 703 & \multirow{3}{*}{$1 / \propto$} \\
\hline CAVITY VOLUME V2 & 425.4 & 523.1 & 803.3 & 921.3 & 1509 & \\
\hline CAVITY VOLUME V3 & 424.4 & 514.4 & 803.6 & 930.7 & 1744 & \\
\hline $\mathrm{CV}$ & $7 \%$ & $1 \%$ & $1 \%$ & $10 \%$ & & \\
\hline CAVITY POSITION V4 & 527.4 & 614.9 & 1015 & 1177 & 289 & \multirow{3}{*}{$\mathrm{f}(\propto)$} \\
\hline CAVITY POSITION V5 & 526.7 & 1006 & 1024 & 1177 & 289 & \\
\hline CAVITY POSITION V6 & 499.6 & 620.8 & 1011 & 1190 & 289 & \\
\hline $\mathbf{C V}$ & $3 \%$ & $30 \%$ & $1 \%$ & $1 \%$ & & \\
\hline CAVITY SHAPE V7 & 499.6 & 621.8 & 1028 & 1184 & 289 & \multirow{3}{*}{$\varnothing$} \\
\hline CAVITY SHAPE V8 & 499.2 & 621.5 & 1025 & 1182 & 289 & \\
\hline CAVITY SHAPE V9 & 499.6 & 620.8 & 1011 & 1190 & 289 & \\
\hline $\mathrm{CV}$ & $0 \%$ & $0 \%$ & $1 \%$ & $0 \%$ & & \\
\hline
\end{tabular}

Table 7. Cavity cases results

V1, V2, V3 results, table 7 shows an inverse volume - frequency relation. Increasing the total volume of cavities from $703 \mathrm{~cm}^{3}$ to $1744 \mathrm{~cm}^{3}$ produces an opposite tendency on the frequency values, F1 and F4 columns show CV values higher than $5 \%$. Attending equation (1), a reverse relation implies that $E I_{\text {bend }}$ term values increase proportionally less than $\rho S$ term when cavity volume increases. Magnitudes defining the volume of the cavity has no relation with axis orientation; nevertheless, wood has one axis orientation with a much higher Young modulus than the other two directions (Table 4). This analysis concludes that the orientation of the cavity defining cross-section relative to $\mathrm{L}, \mathrm{T}$ and $\mathrm{R}$ axis generates different results in terms of modal behaviour. This interaction must be reviewed in detail on future works, creating a dedicated experiment design to model the case entirely. Luthier confirmed that it is a complex parameter that is typically solved using existing guitars as reference. V4, V5, V6 results, table 7 indicate that a constant cavity volume of $289 \mathrm{~cm}^{3}$ located on different positions modifies the values of modal frequencies. Comparison of V4 and V5 options (same cavity in a symmetric position) shows a little variation on F1, F3 and F4 frequencies and an apparent distortion on the F3 value $(1003 \mathrm{~Hz})$. Due to the distorted value appeared, we should review this in detail on future works, creating a dedicated experiment design. Luthier confirmed that is a similar situation as the previous case, solved using existing guitars as reference. V7, V8, V9 results, table 7 show that when cavity volume is constant $\left(289 \mathrm{~cm}^{3}\right)$, changing the cavity shape does not produce significant changes on frequency values. Variation coefficient values are close to zero. We can conclude that cavity shape is not a relevant parameter referring vibrational response. Thus, manufacturing easy geometries, e.g. circular pockets, the luthier saves time and money.

\subsection{Geometric parameters results:}

Next tables show the results of changing primary geometric parameters like body or neck general thickness. This is a common situation on guitar manufacturing, especially on custom made guitars. The influence of these little changes is underestimated in terms of vibrational behaviour most of the times, especially on the neck part. Cases numbered zero are situated as a reference in the middle table zone, so both tables show case id's with thickness values above and beyond the zero reference. Table 8 shows the results of modifying the global thickness of the body part, preserving the external shape design

\begin{tabular}{|c|c|c|c|c|c|c|}
\hline FEM CASE ID & F1 (Hz) & F2 (Hz) & F3 $(\mathbf{H z})$ & F4 (Hz) & Thickness (mm) & Relation \\
\hline BODY THICKNESS 1 & 381,5 & 527,9 & 840,1 & 1014,0 & -7.5 & \multirow{5}{*}{$\propto$} \\
\hline BODY THICKNESS 2 & 406,3 & 560,8 & 889,3 & 1072,5 & -5 & \\
\hline SOLID BODY 0 & 453,2 & 622,4 & 979,5 & 1181,9 & 0 & \\
\hline BODY THICKNESS 3 & 499,5 & 686,1 & 1067,6 & 1291,0 & 5 & \\
\hline BODY THICKNESS 4 & 522,0 & 716,3 & 1108,8 & 1343,2 & 7.5 & \\
\hline CV & $13 \%$ & $13 \%$ & $12 \%$ & $12 \%$ & & \\
\hline
\end{tabular}

Table 8 . Body thickness case results 
BODY THICKNESS: We can see a uniform dispersion of values in the four frequency columns (F1, F2, F3 and F4) in Table 8. Values of CV present variations of 1\%, comparing columns. This behaviour indicates a direct relation; increasing body thickness produces higher modal frequency values. Table 9 applies the same concept as in body thickness, increasing the global neck thickness but preserving the exterior shape design.

\begin{tabular}{|c|c|c|c|c|c|c|}
\hline FEM CASE ID & F1 (Hz) & F2 (Hz) & F3 $(\mathbf{H z})$ & F4 (Hz) & Thickness (mm) & Relation \\
\hline NECK THICKNESS 1 & 177,5 & 388,0 & 428,4 & 541,5 & -2.5 & \multirow{5}{*}{$\alpha$} \\
\hline NECK THICKNESS 2 & 193,8 & 403,8 & 457,2 & 584,7 & -1 & \\
\hline NECK THICKNESS 0 & 205,4 & 418,3 & 474,3 & 611,8 & 0 & \\
\hline NECK THICKNESS 3 & 214,6 & 421,6 & 490,4 & 638,4 & 1 & \\
\hline NECK THICKNESS 4 & 229,1 & 432,9 & 512,0 & 675,9 & 2.5 & \\
\hline $\mathbf{C V}$ & $10 \%$ & $4 \%$ & $7 \%$ & $8 \%$ & & \\
\hline
\end{tabular}

Table 9. Neck thickness case results

NECK THICKNESS: We find less uniform dispersion of values in the four frequency columns (F1, F2, F3 and F4), in Table 9. Values of CV present amounts between 4 and 10\%. These data confirm a direct relation, increasing the neck thickness produces higher modal frequency values. Luthiers confirm the results obtained, when you add material to existing guitar design, values of modal frequencies increase, and the vibration energy is absorbed on higher bands, producing a "darker sound, less brilliant and with damped harmonic content."

\subsection{Wood type results:}

Next tables show the results of changing wood, used to manufacture the body and the neck. Table 10 shows the modal frequency values obtained by changing the material defined in the FEM model for the body part.

\begin{tabular}{|c|c|c|c|c|c|c|}
\hline FEM CASE ID & F1 (Hz) & F2 (Hz) & F3 (Hz) & F4 (Hz) & Wood & Relation \\
\hline BODY WOOD 1 & 446,4 & 548,1 & 919,4 & 1130,5 & Mahogany & \multirow{6}{*}{$f(\propto)$} \\
\hline BODY WOOD 2 & 437,0 & 603,8 & 946,6 & 1163,2 & Ash & \\
\hline BODY WOOD 3 & 423,2 & 512,7 & 886,7 & 1169,9 & Birch & \\
\hline BODY WOOD 4 & 444,0 & 508,0 & 918,8 & 1165,4 & Poplar & \\
\hline BODY WOOD 5 & 428,1 & 558,5 & 918,8 & 1156,2 & Maple & \\
\hline BODY WOOD 6 & 403,6 & 525,8 & 867,8 & 1151,9 & Walnut & \\
\hline CV & $4 \%$ & $7 \%$ & $3 \%$ & $1 \%$ & & \\
\hline
\end{tabular}

Table 10. Body wood results

BODY WOOD: Viewing the frequency values in Table 10, F1, F2, F3 bands are modified by wood type, whilst F4 band has a $1 \%$ coefficient of variation, Table 11 shows the modal frequency values obtained by changing the material defined in the FEM model on the neck part, specifically on the neck part.

\begin{tabular}{|c|c|c|c|c|c|c|}
\hline FEM CASE ID & F1 (Hz) & F2 (Hz) & F3 (Hz) & F4 (Hz) & Wood & Relation \\
\hline NECK WOOD 1 & 204,7 & 421,3 & 474,2 & 610,6 & Mahogany & \multirow{6}{*}{$f(\propto)$} \\
\hline NECK WOOD 2 & 206,2 & 420,9 & 478,9 & 618,1 & Ash & \\
\hline NECK WOOD 3 & 216,7 & 442,0 & 482,1 & 623,0 & Birch & \\
\hline NECK WOOD 4 & 233,1 & 475,3 & 519,1 & 670,9 & Poplar & \\
\hline NECK WOOD 5 & 205,4 & 418,3 & 474,3 & 611,8 & Maple & \\
\hline NECK WOOD 6 & 210,5 & 427,3 & 462,0 & 600,5 & Walnut & \\
\hline $\mathbf{C V}$ & $5 \%$ & $5 \%$ & $4 \%$ & $4 \%$ & & \\
\hline
\end{tabular}

Table 11. Neck wood results 
NECK WOOD: Viewing the frequency values in Table 11, F1, F2, F3 and F4 bands are modified by wood type, we find less uniform dispersion of values than table 10.

\subsection{Manufacturing case summary}

During the investigation progress, a manufacturing case was created at the same time. A hollow-body telecaster model manufactured by an Italian luthier arrived at the workshop, and immediately attracted our attention. This guitar has a round bass sound, opposed to the more mid -trebled sound expected, (that is what traditional knowledge tells us about thin-line models). We decided to apply the results of the ongoing work to replicate this instrument and produce a similar version. Original model cavity layout, body and neck geometry were modelled using combined x-ray scan and laser techniques.

Data obtained from the modal analysis presented in this article, was used to define the design changes needed to manufacture three modified guitars, expecting not losing the original model bass response. Results of the modified guitar's design, shown that the general guidelines obtained from 3D mock-up models were correct. Original guitar weight was reduced significantly (from 2300 gr. to 1950 gr), preserving the original tonal response by modifying cavity position and size and adding $3 \mathrm{~mm}$ thickness to the guitar neck. The optimisation of internal body cavities allowed to satisfy the customer requirement, to have a thicker neck without creating an unbalanced instrument.

\section{Conclusions}

Results show that the relation of modal frequency values and the manufacturing parameters exist in the CAD/CAE environment in different ways (direct, reverse or complex), and can be simulated. Apart from checking these results do not contradict expression (1), we discussed if the results obtained agree with the traditional knowledge of luthiers, as is the case of our co-author David Rossi. Results agreed with the most common rules, for instance, "increasing the thickness of the body part cuts high frequencies in the sound produced", but also expose the areas that demand to be deeply studied in next research stages to create an operational digital twin of the guitar.

Thanks to the results, we identified the following essential areas to guide and improve our research.

- Cavity position and volume.

- Wood and related options (fibre orientation, woodcut and use of combined wood types).

- Vibrational influence of body and neck in the assembly.

- Neck joint modelling.

All of them turned out to be a common topic of discussion with our luthier co-author. Modal frequency values define a vibrational fingerprint of the main electric guitar components (body and neck), that can help the luthier to take decisions about parameters like cavity volume, weight balance of the guitar, total weight, and body neck coupling. This fingerprint is useful to approximate an instrument to another one, changing manufacturing parameters to achieve the desired frequency values.Experimental design and statistics improvement constitutes a key factor in analysing the future more oversized results packages and built the digital model accurately. The information and feedback obtained from the manufactured case were useful in many aspects, so the methodology of running a parallel manufacturing case with the investigation is crucial.

\section{Future works:}

Despite the promising results, areas listed above should be deeply studied in a complete assembly system context, to develop different scenarios of the digital guitar mock-up correctly. Positive feedback obtained guides the research project towards a more extended parameter set, paying particular attention to the guitar neck and neck joint modelling in future stages, due to the more significant influence on the vibrational behaviour of the guitar assembly, as was also mentioned by [3].

\section{References}

[1] Paté, Arthur. (2014). Lutherie de la guitare électrique solid body: aspects mécaniques et perceptifs. PhD. Department, Universite Pierre et Marie Curie,Paris, France.

[2] Zoric, A[nton] \& Kaljun, J[asmin]. (2018). The Influence of the Acoustic Properties of Wood for the production of Electric Solid Body Guitars, Chapter 18 in DAAAM International Scientific Book 2018, pp.195-210, B. Katalinic (Ed.), Published by DAAAM International, ISBN 978-3-902734-19-8.

[3] Navarret, Benoit. (2013). Caractériser la guitare électrique: Définitions, organologie et analyse de données verbales. PhD. Université Vincennes - Saint-Denis. Paris. France.

[4] Forest Product Laboratory (2013). Wood Handbook: Wood as an engineering material, United States Department of Agriculture, ISBN 978-1710055184, USA. 
[5] Fleischer, Helmut \& Zwicker, Tilmann. (1998), Mechanical vibrations of electric guitars. Acta Acustica united with Acustica. 84. 758 - 765, ISSN 0001-7884.

[6] Basic Dynamic Analysis User's Guide (2014). Siemens Product Lifecycle Management Software Inc. Avaliable from:https://docs.plm.automation.siemens.com/resources/nxnastran/10/help/en_US/pdf/basic_dynamics.pdf. Accessed: 2019-11-26

[7] https://www.fender.com/articles/gear/the-one-that-started-it-all-a-telecaster-history. Accessed: 2020-01-20.

[8] Horton, N. G., \& Moore, T. R. (2009). Modelling the magnetic pickup of an electric guitar. American Journal of Physics, 77, 144; https://doi.org/10.1119/1.2990663.

[9] Kröning, O., Dempwolf, K., \& Zölzer, U. (2011). Analysis and simulation of an analog guitar compressor. Avaliable from: http://recherche.ircam.fr/pub/dafx11/Papers/22_e.pdf. Accessed: 2020-06-23.

[10] Cohen, I., \& Hélie, T. (2010). Real-time simulation of a guitar power amplifier. Avaliable from: http://dafx10.iem.at/proceedings/papers/CohenHelie_DAFx10_P45.pdf. Accessed: 2020-04-13. 